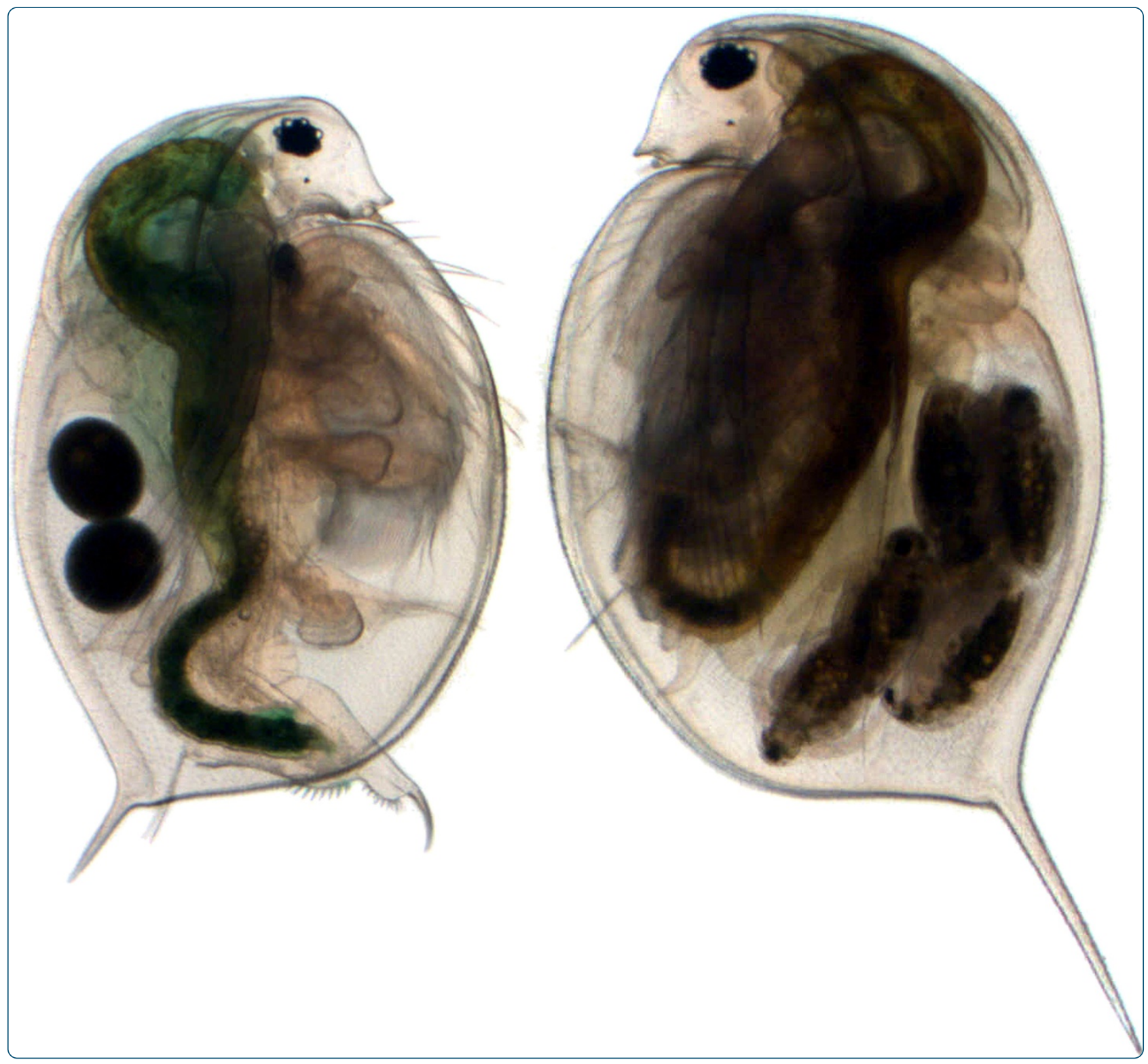

Proteomic analysis of Daphnia magna hints at molecular pathways involved in defensive plastic responses

Otte et al.

C Biomed Central 


\title{
Proteomic analysis of Daphnia magna hints at molecular pathways involved in defensive plastic responses
}

\author{
Kathrin A Otte ${ }^{1,2,3}$, Thomas Fröhlich², Georg J Arnold ${ }^{2}$ and Christian Laforsch ${ }^{3 *}$
}

\begin{abstract}
Background: Phenotypic plasticity in defensive traits occurs in many species when facing heterogeneous predator regimes. The waterflea Daphnia is well-known for showing a variety of these so called inducible defences. However, molecular mechanisms underlying this plasticity are poorly understood so far. We performed proteomic analysis on Daphnia magna exposed to chemical cues of the predator Triops cancriformis. D. magna develops an array of morphological changes in the presence of Triops including changes of carapace morphology and cuticle hardening.

Results: Using the 2D-DIGE technique, 1500 protein spots could be matched and quantified. We discovered 179 protein spots with altered intensity when comparing Triops exposed animals to a control group, and 69 spots were identified using nano-LC MS/MS. Kairomone exposure increased the intensity of spots containing muscle proteins, cuticle proteins and chitin-modifying enzymes as well as enzymes of carbohydrate and energy metabolism. The yolk precursor protein vitellogenin decreased in abundance in 41 of 43 spots.

Conclusion: Identified proteins may be either directly involved in carapace stability or reflect changes in energy demand and allocation costs in animals exposed to predator kairomones. Our results present promising candidate proteins involved in the expression of inducible defences in Daphnia and enable further in depth analysis of this phenomenon.
\end{abstract}

Keywords: Daphnia, Phenotypic plasticity, Inducible defence, Predator-prey interaction, 2D-DIGE, Proteomics

\section{Background}

Phenotypic plasticity describes the ability of a genotype to express different phenotypes in response to varying environmental conditions $[1,2]$. Given that phenotypic plasticity is an important adaptation to face heterogeneous environments it is a fundamental aspect of the ecology and evolution of a broad range of organisms [3].

One frequently changing biotic condition, which strongly influences organisms' fitness and abundance in an ecological community context, is predation [4]. Phenotypic plasticity in defensive traits, so called inducible defences, occur in many species throughout invertebrate, vertebrate and plant taxa [5]. They are especially common in aquatic environments, where prey species can

*Correspondence: christian.laforsch@uni-bayreuth.de

3 Animal Ecology I, Bayreuth University, 95440 Bayreuth, Germany Full list of author information is available at the end of the article easily detect chemical cues (kairomones) released by predators [6].

Important key stone species of fresh water environments are waterfleas (Daphnia: Crustacea). The biology of these animals was studied over the past 250 years [7], resulting in a large amount of literature documenting their ecological diversity. With the help of the Daphnia Genomics Consortium (https:// wiki.cgb.indiana.edu/display/DGC/Home), Daphnia is now one of the leading model organisms in evolutionary and ecological functional genomics. With the published genome sequence of Daphnia pulex [8] and the available pre-release of the Daphnia magna genome sequence (https://wiki.cgb.indiana.edu/display/ DGC/Daphnia+magna+Genome), the American National Institutes of Health (NIH) has added Daphnia to their list of model organisms for biomedical research (http://www. nih.gov/science/models/daphnia/). 
Daphnia shows a multitude of inducible defences in response to changing predator regimes and hence serves as textbook example for phenotypic plasticity in defensive traits (reviewed in [9]). These defences include life history shifts like altered size or age at maturity [10-12], modifications of behaviour, e.g. diel vertical migration [13-15] and morphological changes including the formation of spinelike structures and helmets [16-18]. Also so called hidden morphological defences, which increase the stability of the carapace, were found [19-21].

The description of the $D$. pulex genome unravelled large arrays of environmental specific genes [8], which may be the key players in the formation of phenotypic plastic traits [22]. These genes often reside within the elevated number of tandem duplications, a striking feature of the D. pulex genome [8]. The same seems to be true for the genome of $D$. magna (Colbourne, pers. commun.). However, as molecular tools and genomic resources for Daphnia have only recently become available, the analysis of molecular mechanisms underlying inducible defences in Daphnia exposed to predator kairomones is still in its infancy (summarised in [23]). Up to date, only few studies have been conducted using either candidate gene/protein approaches [24-26] or a microarray approach based on stress and life stage specific cDNA libraries [27] in D. magna.

In these studies, genes involved in protein biosynthesis, protein catabolism and protein folding $[26,27]$ showed different RNA expression patterns between $D$. magna defended against fish or Chaoborus and a control group. Also heat shock proteins, confirmed by western blot analysis, were found to be involved in the anti-predator defence of $D$. magna, being more abundant after shortterm exposure [25] but less abundant after long-term exposure to fish kairomones [24]. Furthermore, two proteins of the cytoskeleton, actin and alpha tubulin, were affected [24].

The availability of enhanced genomic resources for Daphnia not only facilitates candidate gene approaches but also enables holistic approaches. In contrast to candidate approaches, holistic experiments may elucidate unpredicted key players involved in trait formation and regulation of inducible defences in Daphnia. Holistic proteomic analysis is especially suitable, as proteins are the typical effectors of biological functions and protein abundance is not necessarily well correlated with the corresponding mRNA level (e.g. [28,29]).

In the present study, we used the predator-prey system of Triops cancriformis and Daphnia magna for analysis of proteins involved in the formation of inducible defences. D. magna is a common species found in temporary and permanent ponds spreading from temperate regions to arid areas in the Holarctic and Africa [30]. This species shows inducible morphological defences in response to kairomones released by T. cancriformis. These morphological changes result in an increased bulkiness (increased body length, increased body width, increased tail spine length; see Figure 1) and are known to serve as an effective defence against Triops predation [31,32]. In addition, D. magna develops hidden morphological defences when exposed to Triops kairomones, which consist of a harder and thicker cuticle and an increased diameter of cuticle pillars, and therefore enhance carapace stability [21].

\section{Results}

We have studied differentially abundant proteins in $D$. magna exposed to kairomones of the predator T. cancriformis, which is known to induce phenotypic plastic defensive structures in this species [31], and a control group not exposed to predator kairomones. Performing proteomic analysis of adult Daphnia is a challenging task due to very strong proteolytic activity [33-36], which most likely results from proteases expressed in the digestive tract [37]. To avoid proteolytic degradation of protein lysates, we sampled late stage D. magna embryos featuring reduced protease activity. The sensitive period in Daphnia for perceiving chemical cues released by predators and for the formation of defensive traits is known to happen during embryonic development [38]. Preliminary experiments proved the same for D. magna exposed to Triops rendering late embryonic stages perfectly suitable for proteomic analysis.

Proteomic 2D-DIGE analysis and mass spectrometric analysis of abundance altered spots resulted in identification of 69 protein spots with 23 being more intense

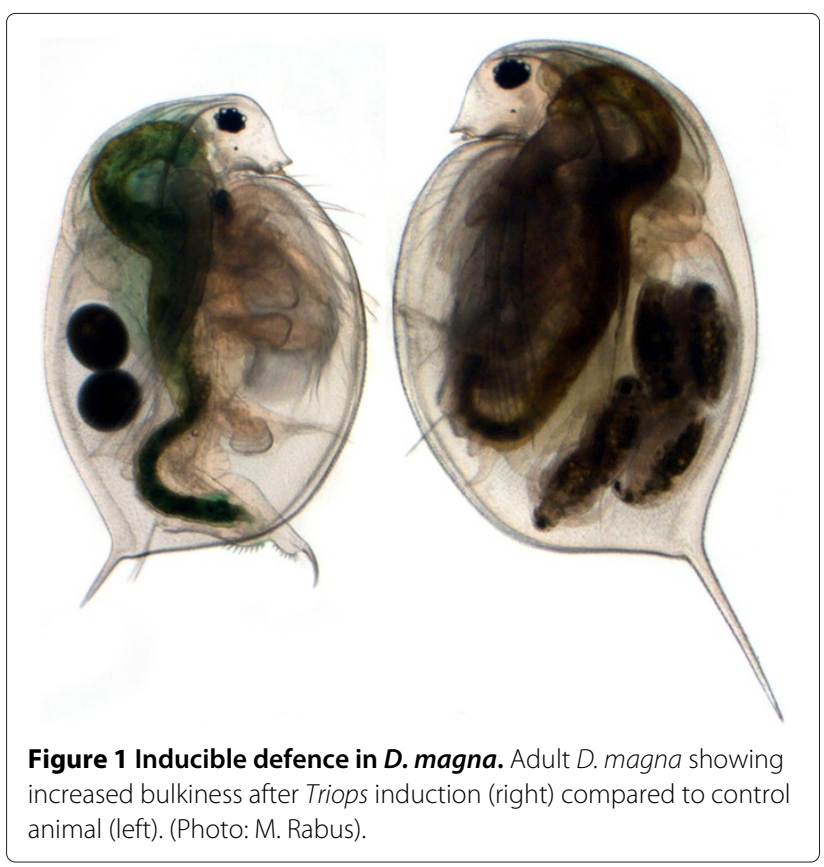


in kairomone exposed animals and 46 less intense. Mass spectrometric data, summarised spot data and further details are provided in the supplementary files (see Additional files 1, 2 and 3).

In detail, three biological replicates of Triops kairomone exposed animals and three biological replicates of a control group were compared using three 2D-DIGE gels. The gel images were of high-quality (see Figure 2 and also Figure 3) with all three gels showing highly reproducible spot patterns (see Additional file 4). In an unsupervised hierarchical cluster analysis, spot patterns clustered in two distinct groups, each containing solely gels from Triops kairomone exposed animals and controls, respectively (see Figure 4).

By software assisted image analysis of 2D-DIGE gels, 1505 spots could be matched, i.e., corresponding spots of the three replicates were assigned in a supervised manner, and the intensity of all matched spots was quantified. 179 spots were found with different intensities between Triops exposed and control Daphnia $(p \leq 0.05$, ratio $\geq|3|)$. Out of these spots, 58 showed increased intensity in gels from Triops exposed animals whereas 121 showed decreased intensity.

87 spots were successfully identified using nano-LC MS/MS. Unambiguous identification of one single protein per spot was possible for 56 spots, while the majority of remaining spots contained contaminating fragments of the yolk protein precursor vitellogenin. The latter spots composed of peptides referring to more than one protein were only included in the bioinformatic analyses, if the total number of assigned peptides for one protein was at least three times higher than the number of all other assigned peptides. The corresponding protein was then regarded to represent the major component.

With respect to these classifications, we identified 69 protein spots in total. Out of this, 23 spots were more abundant in Triops exposed D. magna with 21 spots not containing vitellogenin (see Table 1). Of the remaining 46 spots, which were less abundant in Triops exposed D. magna, only 3 spots contained other proteins than vitellogenin (see Table 2). For vitellogenin-related spots, see the Additional file 2.

More abundant proteins of animals exposed to Triops kairomones (see Table 1) include proteins related to the cuticle (e.g. chitin deacetylase, different cuticle proteins), proteins involved in carbohydrate metabolism (glyceraldehyde-3-phosphate dehydrogenase, fructosebisphosphate aldolase, ATP synthase), proteins related to the muscular system (paramyosin, troponin and actin), phosphorylation (nucleoside diphosphate kinase), glycosylation (phosphomannomutase) and a regulatory 14-3-3 $\zeta$ protein (see Table 1).

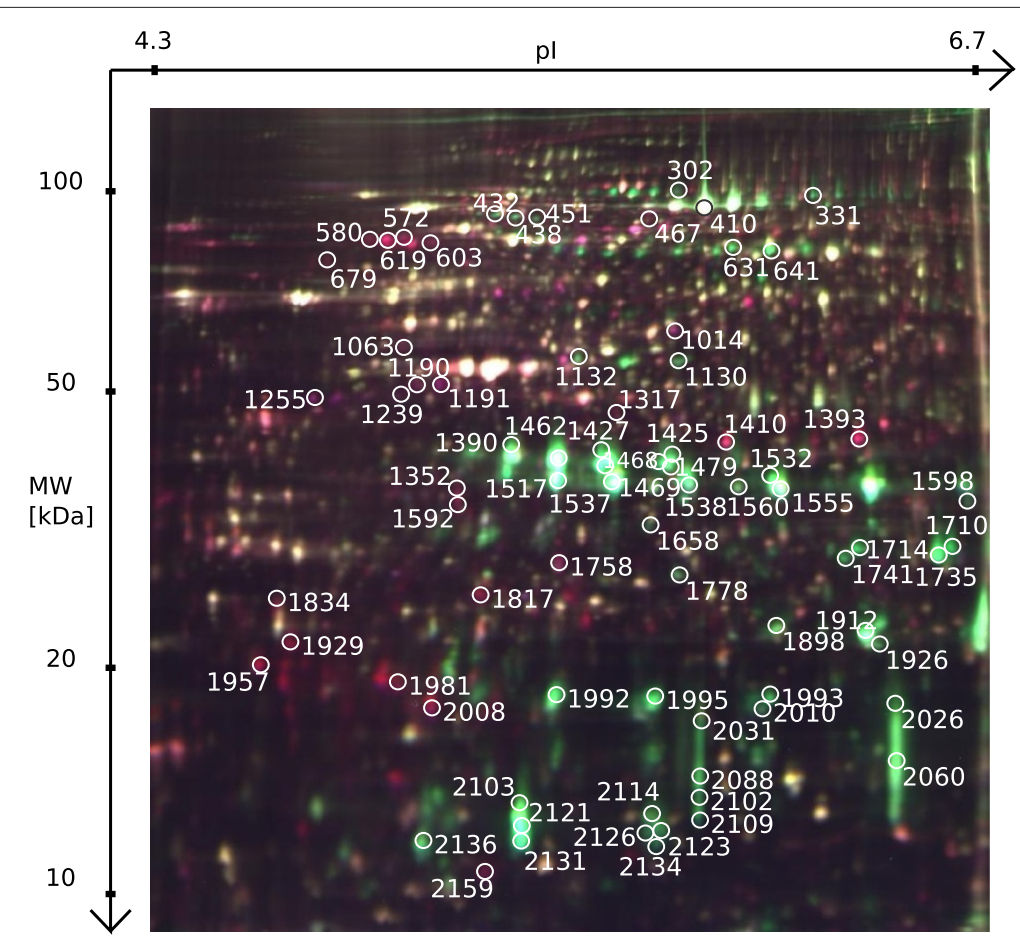

Figure 2 2D DIGE gel for comparing Triops exposed and control $D$. magna embryos. Spots with more abundant proteins in the kairomone exposed group are displayed in red (Cy5 labelled), spots with more abundant proteins in the control group are displayed in green (Cy3 labelled). Spots marked with Spot ID showed significantly different intensity and were successfully identified. Spot IDs not listed in Table 1 or Table 2 refer to vitellogenin-related spots. 

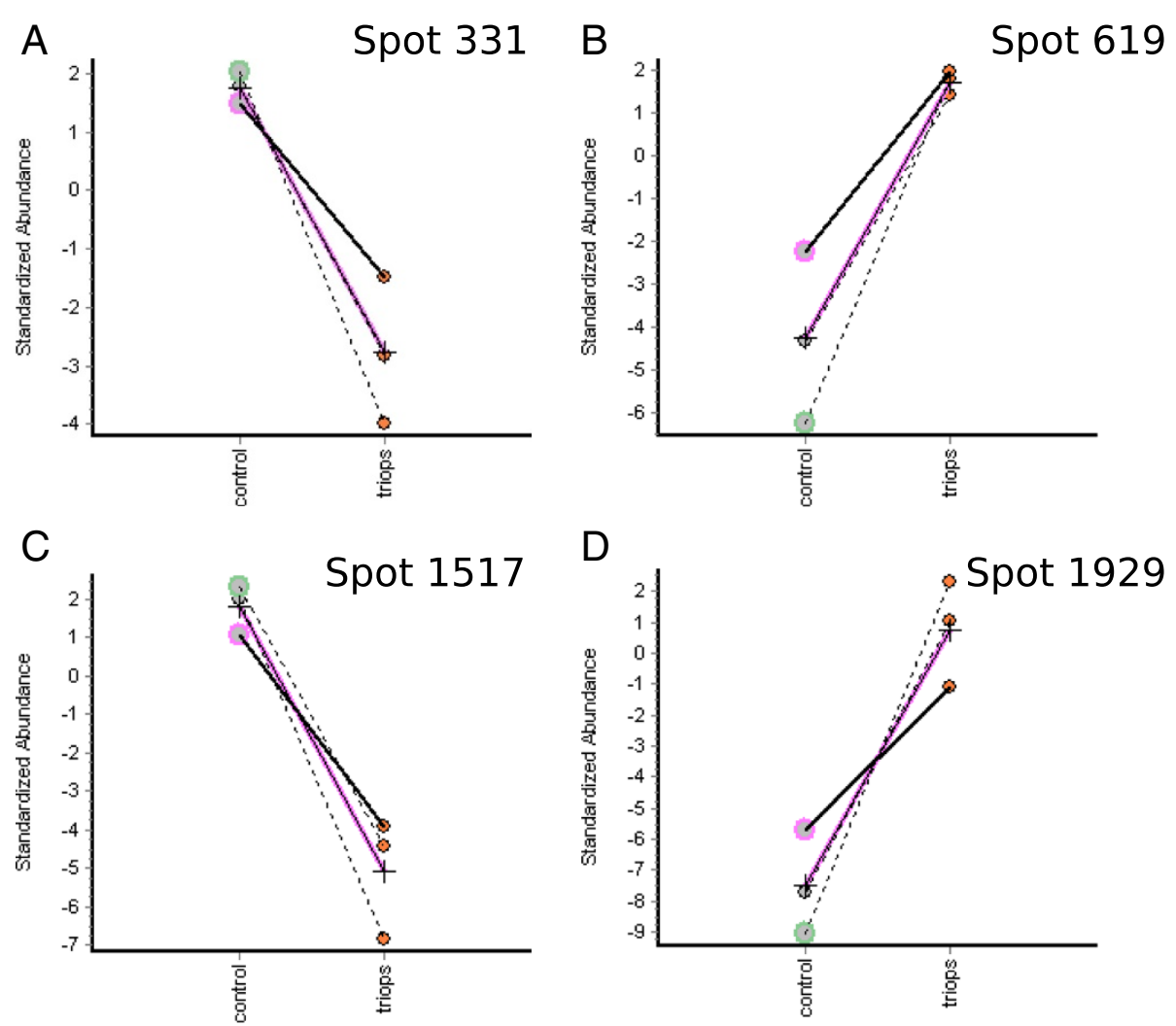

Figure 3 Examples for normalised DIGE intensity ratios. Normalisation was done according to internal pooled standard (IPS), here an abundance of e.g. 2 indicates that abundance is 2 of IPS abundance whereas -2 means $1 / 2$ of IPS abundance. They serve as indicators for changes in protein abundance in kairomone exposed D. magna and in the control group for: Spot 331 - STAT Protein (A); Spot 619 - Chitin deacetylase 2A (B); Spot 1517 - Vitellogenin (C) and Spot 1929 - Cuticle Protein (D).

Less abundant proteins of animals exposed to Triops kairomones (see Table 2) include a protein responsible for larval development called Prohibitin, a transcription activator (STAT) and a heat shock protein (HSP70).

To find grouped protein annotation terms and to visualise their relationships, ClueGO network analysis [39] was conducted using the Gene Ontology and KEGG databases of D. melanogaster (see Figure 5). Four functional groups could be separated, which were related to either glycolysis, actin cytoskeleton, chitin deacetylase activity or nucleoside triphosphate biosynthetic processes.

Comparison of protein data to known tandem duplicated genes in $D$. pulex with three or more duplications resulted in matching of three proteins. One cuticle protein (FBgn0033869, 33 duplications), Actin (3 duplications) and vitellogenin (4 duplications) were found to be tandem duplicated in the $D$. pulex genome.

\section{Discussion}

Predation is a key factor driving natural selection and therefore important for evolution of prey species and dynamics of prey communities [40]. As predator quantity and quality usually show heterogeneous patterns [41], prey species develop a variety of plastic defences in response to changing predator regimes [4]. Predator characteristics, e.g. prey-preference, feeding mechanism, predation strategy and habitat use, play an important role in shaping these plastic defences [42].

Particularly, Daphnia has to cope with a variety of sizeselective predators [43]. Vertebrate predators like visually hunting fish are usually limited in the process of detecting the prey, whereas invertebrate predator like Chaoborus or Triops are often limited at the capturing, handling or ingestion step. Therefore, Daphnia coexisting with fish usually are smaller and more transparent [7] and show avoidance behaviour such as diel vertical migration [13-15]. In response to invertebrate predators, Daphnia often develops morphological defences (e.g. [16-18,31]), which impede capturing, handling or ingestion by the predator.

We studied the defensive responses of D. magna exposed to T. cancriformis, which consist of morphological changes resulting in an increased bulkiness (increased 


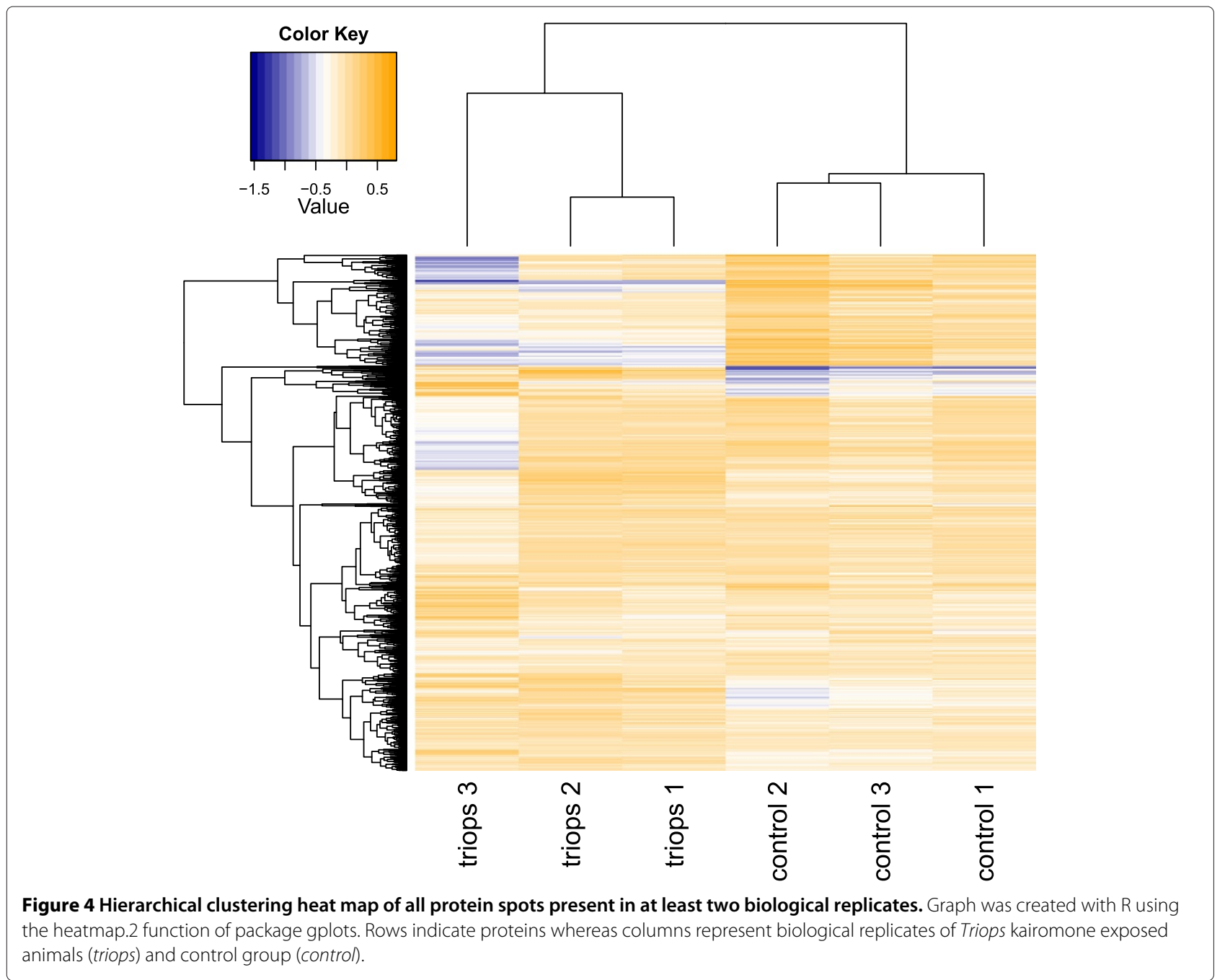

body length, increased body width, increased tail spine length; see Figure 1).

Proteins more abundant in kairomone exposed Daphnia were similar to proteins connected to regulation, carbohydrate metabolism, biosynthetic processes, muscular system or the cuticle (see Table 1). The majority of less abundant proteins was identified as different isoformes of the yolk protein precursor vitellogenin. Three proteins of this data-set (cuticle protein, actin, vitellogenin) are known to be tandem-duplicated in the genome of D. pulex. Tandem-duplicated genes are thought to play an important role in the formation of phenotypic plastic traits [22].

\section{Proteins involved in the formation of inducible defences regulate cell proliferation, participate in signalling pathways and facilitate protein folding}

Two proteins with regulatory function, 14-3-3 $\zeta$ and phosphomannomutase, were of higher abundance in $D$. magna embryos exposed to Triops kairomones in our study.
14-3-3 proteins belong to a family of proteins well conserved among eukaryotes. Two of these isoformes, $\epsilon$ and $\zeta$, have also been identified in D. melanogaster [44] and the silkworm Bombyx mori [45] and were expressed throughout a variety of life stages and in various tissues. 14-3-3 $\zeta$ binds to a large number of partners by recognition of a phosphoserine or phosphothreonine motif and is known to modulate their activity. Phosphomannomutase is an enzyme converting mannose-1-phosphate to mannose-6-phosphate and vice versa. It is therefore important for GDP-mannose synthesis, a molecule involved in glycosylation of proteins. The most similar protein in Drosophila, CG10688, is known to be involved in hypoxia-induced inhibition of protein translation [46]. In kairomone exposed D. magna, phosphomannomutase may therefore provide substrates important for signalling pathways involved in the formation of inducible defences.

Additionally, three proteins with regulatory characteristics, heat shock protein $78 \mathrm{kDa}$, prohibitin and a 
Table 1 More intense spots for kairomone exposed Daphnia in 2D DIGE analysis ( $n=3$ )

\begin{tabular}{|c|c|c|c|c|c|c|c|c|c|}
\hline Spot & GenelD & UniprotID & Protein Name (Organism) & FlybaselD & Ratio & $\begin{array}{l}\text { Mw } \\
\text { theo }\end{array}$ & $\begin{array}{l}\text { Mw } \\
\exp \end{array}$ & $\begin{array}{l}\mathrm{pl} \\
\text { theo }\end{array}$ & $\begin{array}{l}\text { pl } \\
\text { exp }\end{array}$ \\
\hline 1191 & daphmag3mtv317094t1 & Q9NA03 & Actin (Daphnia magna) & FBgn0000046 & $14.3 \pm 1.8$ & 42 & 51 & 5.3 & 5 \\
\hline 2008 & daphmag3mtv3|18463t2 & E9FZ29 & $\begin{array}{l}\text { Putative uncharacterized protein (Daphnia pulex) } \\
\text { Nucleoside diphosphate kinase (Orseolia oryzae) }\end{array}$ & FBgn0000150 & $14 \pm 0.2$ & 17 & 18 & 6.2 & 5 \\
\hline 1255 & daphmag3mtv317094t1 & Q9NA03 & Actin (Daphnia magna) & FBgn0000046 & $13.2 \pm 1.6$ & 42 & 48 & 5.3 & 4.6 \\
\hline 1929 & daphmag3mtv317285t1 & E9GDV0 & $\begin{array}{l}\text { Putative uncharacterized protein (Daphnia pulex) } \\
\text { Cuticle protein (Artemia franciscana) }\end{array}$ & FBgn0033869 & $10.2 \pm 0.7$ & 19 & 22 & 5.7 & 4.5 \\
\hline 1981 & daphmag3mtv318582t2 & E9HPK7 & $\begin{array}{l}\text { Putative uncharacterized protein (Daphnia pulex) } \\
\text { Cuticle protein1c (Daphnia magna) }\end{array}$ & FBgn0086900 & $9.2 \pm 0.6$ & 39 & 19 & 5.1 & 4.9 \\
\hline 1817 & daphmag3mtv317094t1 & Q9NA03 & Actin (Daphnia magna) & FBgn0000046 & $8.6 \pm 0.7$ & 42 & 26 & 5.3 & 5.2 \\
\hline 572 & daphmag3mtv319358t1 & E9HBN5 & $\begin{array}{l}\text { Putative uncharacterized protein (Daphnia pulex) } \\
\text { Chitin deacetylase } 2 \mathrm{~A} \text { (Tribolium castaneum) }\end{array}$ & FBgn0261341 & $7.7 \pm 0.1$ & 59 & 81 & 5.2 & 4.9 \\
\hline 572 & daphmag3mtv317734t1 & E9HBN3 & $\begin{array}{l}\text { Putative uncharacterized protein (Daphnia pulex) } \\
\text { Chitin deacetylase } 1 \text { (Tribolium castaneum) }\end{array}$ & FBgn0260653 & $7.7 \pm 0.1$ & 62 & 81 & 5 & 4.9 \\
\hline 619 & daphmag3mtv319358t1 & E9HBN5 & $\begin{array}{l}\text { Putative uncharacterized protein (Daphnia pulex) } \\
\text { Chitin deacetylase 2A (Tribolium castaneum) }\end{array}$ & FBgn0261341 & $6.2 \pm 0.1$ & 59 & 79 & 5.2 & 5 \\
\hline 1957 & daphmag3mtv3120379t3 & E9HPJ8 & $\begin{array}{l}\text { Putative uncharacterized protein (Daphnia pulex) } \\
\text { Cuticle protein } 1 \mathrm{~b} \text { (Daphnia magna) }\end{array}$ & FBgn0000551 & $5.3 \pm 0.6$ & 22 & 21 & 5.5 & 4.4 \\
\hline 2159 & daphmag3mtv3|10909t1 & E9FQP0 & ATP synthase subunit beta (Daphnia pulex) & FBgn0010217 & $5.2 \pm 0.2$ & 56 & 11 & 5.4 & 5.2 \\
\hline 603 & daphmag3mtv319358t1 & E9HBN5 & $\begin{array}{l}\text { Putative uncharacterized protein (Daphnia pulex) } \\
\text { Chitin deacetylase 2A (Tribolium castaneum) }\end{array}$ & FBgn0261341 & $4.6 \pm 0.2$ & 59 & 80 & 5.2 & 5 \\
\hline 603 & daphmag3mtv317734t1 & E9HBN3 & $\begin{array}{l}\text { Putative uncharacterized protein (Daphnia pulex) } \\
\text { Chitin deacetylase } 1 \text { (Tribolium castaneum) }\end{array}$ & FBgn0260653 & $4.6 \pm 0.2$ & 62 & 80 & 5 & 5 \\
\hline 1393 & daphmag3mtv3121933t1 & E9GF36 & $\begin{array}{l}\text { Glyceraldehyde-3-phosphate dehydrogenase } \\
\text { (Daphnia pulex) }\end{array}$ & FBgn0001092 & $4.2 \pm 0.3$ & 19 & 43 & 5.9 & 6.4 \\
\hline 1758 & daphmag3mtv3121417t1 & E9HCF1 & $\begin{array}{l}\text { Putative uncharacterized protein (Daphnia pulex) } \\
\text { Probable phosphomannomutase (Drosophila } \\
\text { melanogaster) }\end{array}$ & FBgn0036300 & $4.2 \pm 1$ & 16 & 28 & 7.9 & 5.4 \\
\hline 1063 & daphmag3mtv3110909t1 & E9FQPO & ATP synthase subunit beta (Daphnia pulex) & FBgn0010217 & $3.9 \pm 0$ & 56 & 58 & 5.4 & 4.9 \\
\hline 1239 & daphmag3mtv317094t1 & Q9NA03 & Actin (Daphnia magna) & FBgn0000046 & $3.8 \pm 1.1$ & 42 & 49 & 5.3 & 4.9 \\
\hline 467 & daphmag3mtv314480t1 & E9HSV9 & Paramyosin (Daphnia pulex) & FBgn0003149 & $3.5 \pm 0.1$ & 104 & 85 & 5.5 & 5.7 \\
\hline 679 & daphmag3mtv3|9455t1 & E9HEE5 & $\begin{array}{l}\text { Putative uncharacterized protein (Daphnia pulex) } \\
\text { Troponin H isoform } 1 \text { (Apis mellifera) }\end{array}$ & FBgn0004028 & $3.5 \pm 0.3$ & 44 & 74 & 4.8 & 4.7 \\
\hline 1410 & daphmag3mtv3|8855t1 & E9GJ13 & Fructose-bisphosphate aldolase (Daphnia pulex) & FBgn0000064 & $3.5 \pm 0.5$ & 40 & 42 & 6.7 & 6 \\
\hline 1834 & daphmag3mtv317635t2 & E9H1W5 & $\begin{array}{l}\text { Putative uncharacterized protein (Daphnia pulex) } \\
\text { 14-3-3 zeta (Artemia franciscana) }\end{array}$ & FBgn0004907 & $3.5 \pm 0$ & 39 & 25 & 8.5 & 4.5 \\
\hline 1190 & daphmag3mtv317094t1 & Q9NA03 & Actin (Daphnia magna) & FBgn0000046 & $3.3 \pm 0.7$ & 42 & 51 & 5.3 & 5 \\
\hline 1352 & daphmag3mtv3|16198t1 & E9GE24 & $\begin{array}{l}\text { Putative uncharacterized protein (Daphnia pulex) } \\
\text { Retinol dehydratase (Danaus plexippus) }\end{array}$ & FBgn0033887 & $3 \pm 0.1$ & 39 & 45 & 6.3 & 6.5 \\
\hline
\end{tabular}

Spots were identified with LC-MS/MS and annotated using blastp algorithm against NCBI nr database. Spots related to vitellogenin were not shown. 
Table 2 Less intense spots for kairomone exposed Daphnia in 2D DIGE analysis ( $n=3$ )

\begin{tabular}{|c|c|c|c|c|c|c|c|c|c|}
\hline Spot & GeneID & UniprotID & Protein Name (Organism) & FlybaseID & Ratio & $\begin{array}{l}\text { Mw } \\
\text { theo }\end{array}$ & $\begin{array}{l}M w \\
\exp \end{array}$ & $\begin{array}{l}\text { pl } \\
\text { theo }\end{array}$ & $\begin{array}{l}\mathrm{pl} \\
\exp \end{array}$ \\
\hline 1658 & daphmag3mtv317424t1 & E9GTZ4 & $\begin{array}{l}\text { Putative uncharacterized protein (Daphnia pulex) } \\
\text { Prohibitin protein WPH (Danaus plexippus) }\end{array}$ & FBgn0002031 & $-3.5 \pm 0.2$ & 30 & 32 & 5.8 & 5.7 \\
\hline 331 & daphmag3mtv3110027t1 & E9G1W0 & $\begin{array}{l}\text { Putative uncharacterized protein (Daphnia pulex) } \\
\text { Signal transducer and activator of transcription } \\
\text { (Artemia franciscana) }\end{array}$ & FBgn0016917 & $-4.1 \pm 0.1$ & 63 & 92 & 7.3 & 6.5 \\
\hline 631 & daphmag3mtv312732t1 & E9GIU3 & $\begin{array}{l}\text { Putative uncharacterized protein (Daphnia pulex) } \\
\text { Heat shock protein (Culex quinquefasciatus) }\end{array}$ & FBgn0026761 & $-10.1 \pm 1.2$ & 78 & 78 & 6.5 & 6 \\
\hline
\end{tabular}

Spots were identified with LC-MS/MS and annotated using blastp algorithm against NCBI nr database. Spots related to vitellogenin were not shown. 


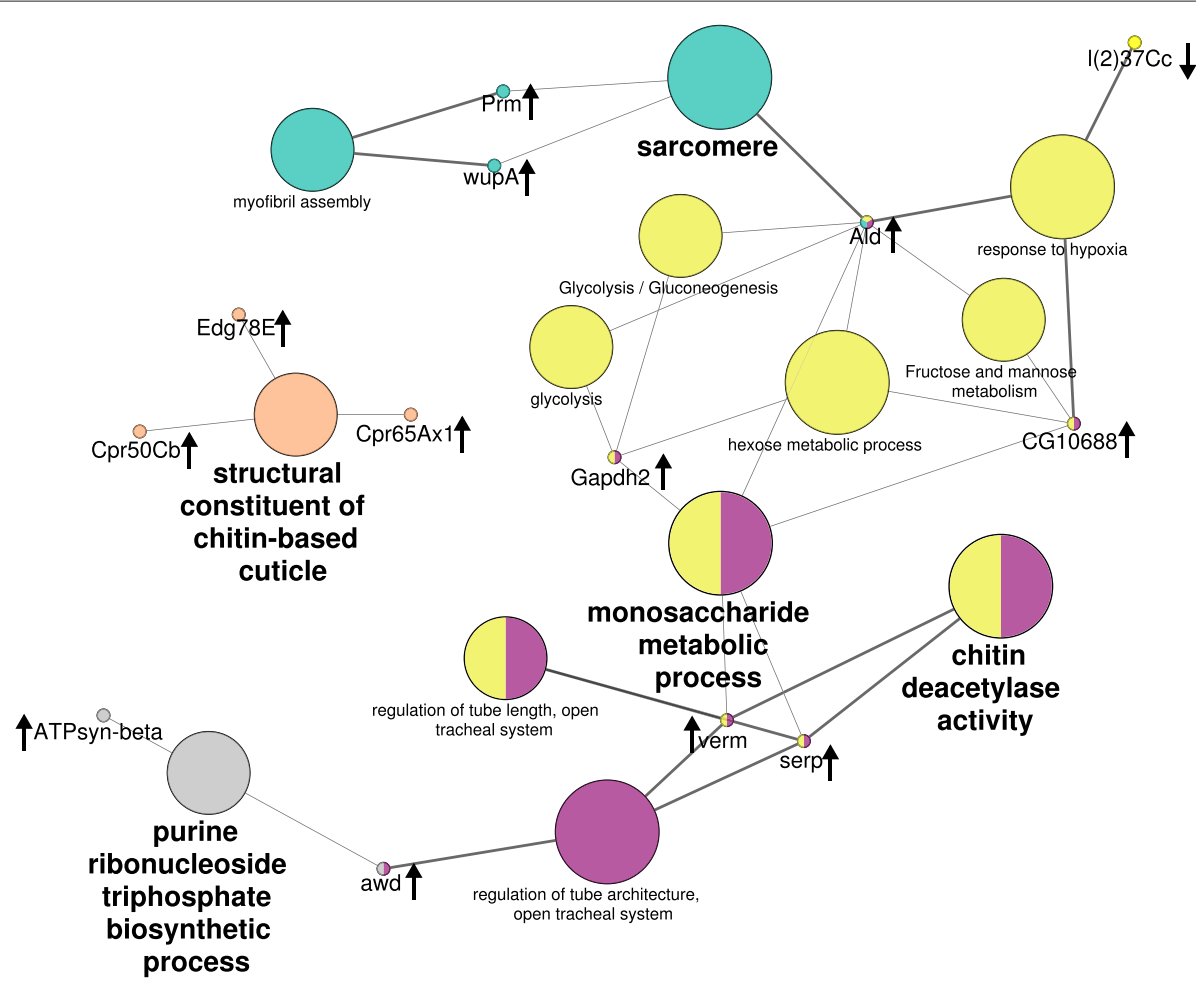

Figure 5 Annotation term network created with ClueGo using functional annotation analysis (two-sided hypergeometric test, Benjamini-Hochberg-correction, kappa-score $\geq \mathbf{0 . 3}$ ). FlybaselDs of proteins with increased and decreased abundance were searched against GO and KEGG databases. Small circles show involved genes and large circles refer to GO terms. Arrows next to gene names indicate decreased or increased abundance. Colours represent grouping of GO terms whereas size of circle and circle label illustrate the corrected p-value. Abbreviated Drosophila gene names correspond to the following protein names (compare also Tables 1 and 2): Ald - Fructose-Bisphosphate aldolase, ATPsyn-beta - ATP synthase beta, awd - Nucleoside diphosphate kinase, CG10688 - Phosphomannomutase, Cpr50Cb - Cuticle protein, Cpr65Ax1 Cuticle protein 1c, Edg78E - Cuticle protein 1b, Gapdh2 - GAPDH, I(2)37Cc - Prohibitin, Prm - Paramyosin, serp - Chitin deacetylase 1, verm - Chitin deacetylase 2A, wupA - Troponin.

transcription activator (STAT), were less abundant in D. magna embryos exposed to Triops kairomones.

Heat shock proteins (HSP) act as chaperones facilitating protein folding and unfolding and play an important role in both, normal cellular homoeostasis and stress response [47]. Pijanowska and Kloc [24] found a decrease in the levels of HSP40, HSP60 and HSP70 when exposing D. magna from birth until first reproduction to either fish or Chaoborus kairomones. These findings corresponds to our findings, we also found a strong decrease in a $78 \mathrm{kDa}$ HSP in Daphnia long-term exposed to Triops kairomones. Reducing HSP expression may save resources under long-term stressful conditions [48]. In addition, another study using D. magna shows that animals with a high tolerance against cadmium exposure display lower levels of HSP70 than animals having a lower tolerance [49]. The same may hold true for D. magna experiencing constant predation stress exerted by Triops.

Prohibitin is a ubiquitously expressed and well conserved protein, which is thought to be a negative regulator of cell proliferation in mammalian cells [50]. The similar protein in Drosophila, lethal (2) 37Cc, is most strongly expressed during late embryogenesis and may play a role in cuticle synthesis because of its presence during molts [51]. Therefore it seems possible, that the lower abundance of this protein may reflect changes of cuticle synthesis during the formation of morphological defences in D. magna.

The sequence of signal transducer and activator of transcription (STAT) protein is most similar to Stat92E in Drosophila. Stat92E is a signal protein and transcription factor in the well characterised JAK/STAT signalling pathway important for processes such as cellular proliferation, especially during embryonic development, immune response and stem cell maintenance [52]. Interestingly, Stat92E shows opposing influence on cell proliferation depending on developmental stage. During early development, Stat92E promotes cell proliferation whereas in later larval stages it reduces proliferation [53]. The under representation of this protein in late-stage $D$. magna embryos exposed to Triops kairomones may reflect a changed cell 
proliferation pattern during the formation of inducible defences.

\section{Proteomic evidence for enhanced energy demand and biosynthetic activity as a consequence of kairomone exposure}

The more abundant proteins glyceraldehyde-3-phosphate dehydrogenase (GAPDH), fructose-bisphosphate aldolase (Ald), ATP synthase subunit beta (ATPsyn-beta) and nucleoside diphosphate kinase (NDK) are related to energy metabolism and biosynthetic processes (see also Figure 5). Both, GAPDH and Ald are key enzymes of the glycolytic degradation of glucose. In addition, GAPDH provides NADPH for biosynthesis of fatty acids, amino acids and nucleic acids. ATP-Syn-beta is a subunit of ATP-Synthase, which catalyses ATP synthesis within the respiratory chain. NDK provides nucleoside triphosphates for a variety of biosynthetic pathways.

Enhanced biosynthesis has already been reported in D. magna exposed to Chaoborus or fish kairomones [26]. D. magna showed a decreased body length when exposed to the vertebrate predator and an increase in body length when exposed to the invertebrate predator. RNA levels of protein biosynthesis related genes were increased for both treatments with higher levels in the fish kairomone treatment indicating a higher energy demand in predator exposed animals.

Another protein related to energy metabolism is vitellogenin, the precursor of the major yolk protein vitellin. Yolk proteins serve as an energy supply as well as organic building blocks throughout embryonic development of oviparous animals [54]. They are usually synthesised in extra ovarian tissues like the insect fat body [55] or non-mammalian vertebrate liver [56] and are taken up by the developing oocyte. During this process, usually referred to as vitellogenesis, vitellogenin is modified through cleavage, phosphorylation, glycosylation and lipidation [57]. At the time of embryogenesis, yolk proteins are further processed and degraded for embryo nutrition [58].

Due to the various processing steps during vitellogenesis and embryogenesis, the frequent occurrence of different vitellogenin related protein spots in 2D-gels of D. magna embryos found in our study is not surprising. Most of the spots were protein fragments with strong isoelectric point (pI) shifts and much smaller molecular weight (MW) compared to theoretical MW (see Additional file 2). Of the 43 vitellogenin-related protein spots found in our proteomic analysis, only 2 proteins were more abundant in Triops exposed D. magna whereas 41 were less abundant. Therefore, predator exposure seems to influence either the total amount of vitellogenin per egg provided by the mother or the yolk utilisation through the embryo because of higher energy demands.
Other studies also found yolk protein dynamics influenced by predator-released kairomones $D$. magna exposed to fish or Chaoborus. The proportion of total yolk used for egg production remained constant [59]. In presence of fish kairomones, $D$. magna reproduced not only earlier and at a smaller body size, but also had a higher number of offspring and this offspring had a smaller body size when compared to a control group $[60,61]$. In the presence of Chaoborus, D. magna reached maturity later at an increased body size and had a smaller number of offspring with larger body size [62]. Triops kairomones seems to increase both, the number and the size of offspring in D. magna [31,63]. Therefore, less yolk may be distributed to a single egg. However, the under representation of vitellogenin spots in kairomone exposed D. magna embryos found in this study may also indicate a higher energy demand. In addition, the higher abundance of other proteins related to energy metabolism and biosynthetic processes mentioned previously supports an increased energy demand of the embryo while building up Triops-induced defensive structures.

\section{Kairomone exposure of Daphnia increases levels of proteins necessary for reinforcement of the muscular system}

The muscle related proteins actin, troponin and paramyosin were all more abundant in Triops exposed D. magna embryos (see also Figure 5). Actin was found in four different protein spots with molecular weight (MW) higher than the theoretical value and acidic pI shifts, indicating posttranslational modifications. Additionally, one protein spot had a considerably smaller MW indicating a cleaved fragment (see Table 1). Actin is a major component of the cytoskeleton as well as of muscle fibres and is now one of the most abundant and highly conserved proteins in eukaryotes usually encoded in multiple genes [64].

Comparing the actin sequences using blastp algorithm, the most similar sequence in D. melanogaster for daphmag3mtv7094t1 is Act87E (FBgn0000046), whereas daphmag3mtv3115317t1 was most similar to Act5C (FBgn0000042). Act87E is known to be expressed in the body wall muscles during embryonic, pupal and adult stages while Act $5 \mathrm{c}$ is a ubiquitous cytoplasmic actin, being expressed throughout all life stages [65]. However, Röper et al. [66] showed that muscle-specific actin is incorporated into cytoplasmic structures, and cytoskeletal actin is incorporated into muscles for all actin paralogues of $D$. melanogaster. Therefore, it is not possible to deduce the function of actin only from its protein sequence.

Actin was connected to the formation of inducible defence in $D$. magna with contradictory results so far. Pijanowska and Kloc [24] reported a strong decrease of actin protein level in D. magna exposed to either 
Chaoborus or fish predation using western blot analysis. On the contrary, Schwarzenberger et al. [26] found a moderate increase of actin mRNA expression in D. magna exposed to fish and only a slight decrease in D. magna exposed to Chaoborus using real-time qPCR. These inconsistent results may be a consequence of the different classes of molecules addressed in these studies, since RNA expression is not a reliable surrogate marker for protein expression.

In our proteomic analysis, strong evidence for a higher abundance of one muscle-specific actin and one cytoplasmic actin was found. In addition, two other musclespecific proteins, troponin and paramyosin were more abundant in D. magna exposed to Triops kairomones. Troponin is an actin-binding protein found in thin filament of vertebrate and invertebrate muscle where it regulates actomyosin activity in a $\mathrm{Ca}^{2+}$ dependant manner [67]. Paramyosin is part of the thick filament of invertebrate muscle and a central player in regulating its diameter, with filaments of increased diameter showing an increased paramyosin:myosin ratio [68]. Predatorinduced increase of muscle size has been found in other organisms, e.g. in the blue mussel Mytilus edulis [69] and in tadpoles of Rana lessonae, in the latter case it improved swimming performance. This may also be the case for defended Daphnia, as D. magna exposed to Chaoborus or fish kairomones show increased escape response time and higher behavioural alertness [24]. In addition, increasing muscular mass may also compensate for the consequences of carapace fortification or altered hydrodynamics resulting from a changed carapace morphology.

\section{Cuticle proteins and chitin-modifying enzymes may cause carapace fortification in kairomone exposed Daphnia}

In T. cancriformis exposed D. magna embryos, five proteins related to exoskeleton show a higher abundance. Out of this, three proteins were similar to cuticle proteins and two proteins were similar to chitin-modifying enzymes (see also Figure 5).

The carapace of D. magna consists of a chitinous integument folded back on itself with a small haemocoelic space in between. Inner and outer integument are connected by pillars as supporting structures [70]. This integument can be separated in the extracellular cuticle and the cellular epidermis. The cuticle consists of the two layers, epi- and procuticle [71]. In arthropods, epicuticle is mainly built out of proteins and lipids and procuticle is made of chitin filaments embedded in a proteinaceous matrix [72]. The properties of cuticle depend highly on the amount and combination of included proteins [73] and also on the degree of acetylation, which may influence cross-linking between protein matrix and chitin filaments [74].
Searching the sequences of the three cuticle proteins more abundant in kairomone exposed D. magna embryos against the prosite database for protein domains ([75], [http://prosite.expasy.org/prosite.html]) revealed chitinbinding domains in all three sequences. Consensus sequences were of the so called R\&R type [76], with all proteins containing one or two RR-2 subgroups, usually associated with hard cuticles [77]. In addition, daphmag3mtv317285t1 also has a short consensus sequence of the RR-1 type, usually found in soft cuticles.

As further chitin modifying enzymes, we found chitin deacetylase type 1 and $2 \mathrm{~A}$ in three different spots at around $80 \mathrm{kDa}$. These two proteins have a very similar molecular weight and $\mathrm{pI}$ and were therefore not well discriminated on the 2D-Gel. Molecular weight of these two proteins was $20 \mathrm{kDa}$ higher than expected and $\mathrm{pI}$ was slightly smaller than computed pI (see Table 1), which indicates different states of post-translational modifications within the three different spots. Chitin deacetylase is a chitin modifying enzyme, which catalyses $\mathrm{N}$-deacetylation of chitin and therefore changes protein binding affinity of chitin filaments. In Tribolium castaneum, several types of chitin deacetylase have been identified, with type 1 and 2 mainly expressed in the exoskeletal epidermis [78]. RNAi experiments revealed lethal phenotypes when using dsRNA corresponding to this chitin deacetylases. Here, animals failed to shed their old cuticles because the new synthesised cuticle lacked mechanical strength [78]. These findings support that these chitin modifying enzymes are involved in forming a harder cuticle in predator exposed D. magna.

Fortification of the exoskeleton in response to predator kairomones is known to play a role in inducible defences of some Daphnia species. D. middendorffiana exposed to the predatory copepod Heterocope septentrionalis shows increased cuticle thickness and cuticle strength [19]. Furthermore, D. pulex and D. cucullata exposed to Chaoborus larvae increase cuticle hardness and D. cucullata shows increased cuticle thickness and increased diameter of the cuticular pillars [20]. Recently, similar hidden defences were also found in D. magna exposed to Triops kairomones, revealing increased cuticle hardness, thickness and pillar diameter [21]. Carapace fortification is thought to act as protection against invertebrate predation, e.g. by increasing the escape efficiency of prey when being caught by the predator [20]. Cuticle related proteins with a higher abundance in D. magna exposed to Triops, i.e. $\mathrm{R} \& \mathrm{R}$ cuticle proteins as well as chitin deacetylases, may be involved in the necessary changes of chitin cross-linking with matrix proteins already in late stage D. magna embryos, causing increased carapace stability. 


\section{Conclusion}

In our proteomic analysis, we found evidence that proteins related to cuticle, muscular system, energy metabolism and regulatory proteins are involved in the phenotypic plastic changes induced by Triops kairomones in D. magna. Cuticle proteins and the cuticle modifying enzymes chitin deacetylases 1 and 2A seem to be directly involved in the formation of morphological changes of the carapace, possibly altering chitin cross-linking with matrix proteins and therefore strengthen carapace stability. The same holds true for changes in abundance of muscle proteins (actin, paramyosin and troponin), which may adjust the muscular system to altered carapace morphology and enabling behavioural changes. Furthermore, proteins not directly involved in building up morphological traits were either involved in energy metabolism and biosynthetic processes or had regulatory functions. These proteins may reflect necessary changes in metabolism needed for the formation of inducible defences. The altered levels of regulatory proteins provide first evidence on signalling pathways possibly involved in the formation of inducible defences i.e. the Ras-mediated signalling pathways (14-3-3 $\zeta$ ), glycosylation (Phosphomannomutase), protein folding (Heat shock protein), regulation of cuticle synthesis (Prohibitin) and translation regulation (STAT).

Our holistic proteomic analysis revealed promising candidate proteins involved in phenotypic plastic response of Daphnia magna exposed to kairomones of the predator Triops cancriformis. Proteins altered in abundance were either directly involved in the formation of defensive traits or reflect involved regulatory or metabolic pathways. Most interestingly, three proteins connected to this inducible defence (cuticle protein, vitellogenin, actin) belong to known tandem duplicated genes in D. pulex, a genetical design occurring in elevated numbers in the D. pulex and possibly also in the D. magna genome [8] which is predicted to play an important role in phenotypic plasticity [22].

Hence, our study fosters the knowledge on the molecular mechanisms of defensive trait formation, i.e. carapace fortification and - even more important - on the costs affiliated with the formation of the defence, since costs are thought to be a crucial premise for the plastic expression of a trait, and therefore a prerequisite for the evolution of phenotypic plasticity.

\section{Methods}

\section{Induction experiment}

All experiments reported in this study were conducted in agreement to the animal protection act of Germany. The induction experiment was carried out using a laboratory cultured clone of $D$. magna $\left(K_{3} 4 J\right)$ originating from a former fish pond near Munich, Germany. This clone shows strong morphological plasticity, i.e. increased body length, increased body width, increased tail spine length and increased carapace strength, in response to Triops predation [21,31,32]. A laboratory cultured clonal line of T. cancriformis provided by Dr. E. Eder, Zoological Institute, University of Vienna served as the predator. The experimental setup was installed in a climate chamber at a constant temperature of $20^{\circ} \mathrm{C} \pm 1^{\circ} \mathrm{C}$ combined with fluorescent lighting at a constant photoperiod $(15 \mathrm{~h}$ day $: 9 \mathrm{~h}$ night).

The induction experiment included three biological replicates per group. For each replicate, 20 daphnids were raised in $2 \mathrm{~L}$ beakers containing $1.5 \mathrm{~L}$ semi-artificial medium [31] and a net cage (mesh width $400 \mu \mathrm{m}$; see Figure 6). The net cage contained one Triops for the kairomone exposed group allowing chemical cues to pass but preventing the daphnids from getting eaten (one Triops/1.5 L). Dead predators were replaced and feces of the predator were removed on a daily basis. For the control group, a net cage without a predator was placed into the beaker. Every second day, half of the artificial medium was exchanged. Daphnids were fed daily with Scenedesmus obliquus at a carbon concentration of $1 \mathrm{mg} \mathrm{L}^{-1}$. Triops

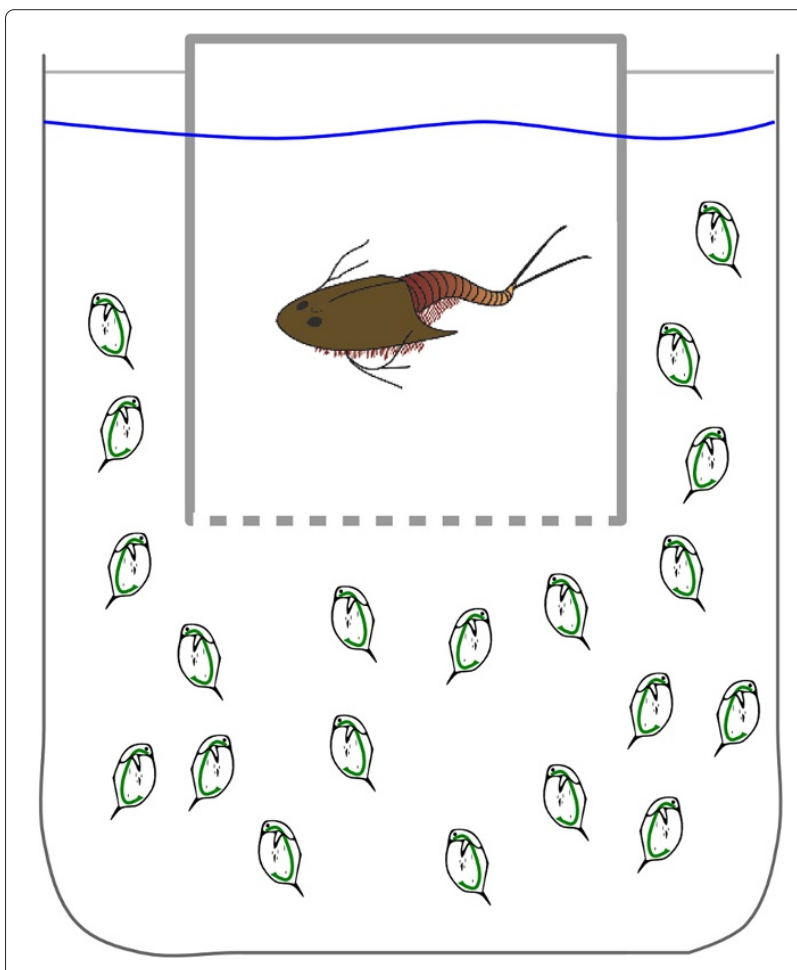

Figure $\mathbf{6}$ Setup of induction experiment. One replicate consists of one beaker with daphnids and a net cage containing the predator, so that daphnids perceive chemical cues of Triops but were prevented from being eaten. For the control group, the net cage was empty. 
were also fed every day with living chironomids larvae, and 10 adult dead D. magna to take prey-specific alarm cues into account. These cues are released when prey animals are crushed by the predator and are also known to induce defensive structures in Daphnia [79]. Daphnia were killed using carbon-dioxide saturated water shortly before feeding. Preliminary experiments have shown that chironomids larvae do not induce defences in Daphnia.

The timetable of the induction experiment followed previous studies of inducible defences in the D. magna Triops system $[21,31,32]$. The experiment was started by placing 4 age-synchronised randomly chosen primiparous daphnids and one adult Triops with a body length between $30 \mathrm{~mm}$ and $40 \mathrm{~mm}$ into the system. After releasing their first clutch, adult daphnids were removed and neonates were randomly reduced to 20 individuals $\left(\mathrm{F}_{0}\right.$ generation) per beaker. $\mathrm{F}_{0}$ mothers were also removed after releasing their first clutch and $F_{1}$ neonates were again reduced to 20 individuals. The same was done after the birth of the next generation $\left(\mathrm{F}_{2}\right)$. The experiment was stopped after three generation cycles (approximately four weeks). After this duration morphological changes are known to be established in all animals of the kairomone exposed group [21,31,32]. In the end, $F_{2}$ generation animals bear their first clutch with embryos of a late developmental stage (black-eye embryos). Hence, age-synchronisation of embryos was in a time range of 12 hours. These embryos were used for proteomic analysis and therefore rinsed out of the mothers' brood pouch and washed twice using autoclaved and filtered semi-artificial medium [31] (filter pore size $0.2 \mu \mathrm{m}$ ). Subsequently, embryos were placed into one tube per biological replicate and snap-frozen using liquid nitrogen. Each replicate consisted of $300-$ 400 embryos.

\section{D-DIGE}

To prepare Daphnia embryos for 2D fluorescence difference gel electrophoresis (2D-DIGE) analysis, the frozen samples were homogenised in a mortar under liquid nitrogen thus preventing thawing. The resulting powder was solubilised in lysis buffer $(2 \mathrm{~mol} / \mathrm{L}$ Thiourea, 6 mol/L Urea, 4\% CHAPS, 1 cOmplete ULTRA Tablets Mini (Roche) per $5 \mathrm{ml}$ buffer) at a concentration of 1 embryo $\mu \mathrm{L}^{-1}$ buffer. Afterwards, each sample was centrifuged using a QIA Shredder Mini Spin Column (Qiagen) for 2 $\mathrm{min}$ at $14,000 \mathrm{~g}$. Sample $\mathrm{pH}$ was adjusted to $8.5 \mathrm{using}$ $50 \mathrm{mmol} / \mathrm{L} \mathrm{NaOH}$. Protein concentration was analysed by performing a Bradford Protein Assay (Coomassie Plus (Bradford) Assay Reagent, Thermo Scientific) according to the manufacturer's instructions.

$50 \mu \mathrm{g}$ protein per biological replicate were labelled with 2D-DIGE Cy3 Dye for control or Cy5 Dye for kairomone exposed group (GE Healthcare Life Sciences) following the protocol of the manufacturer. In addition, an internal standard (IPS) was prepared by pooling all biological replicates and labelling $200 \mu \mathrm{g}$ of this IPS with 2D-DIGE Cy2 Dye.

$24 \mathrm{~cm}$ gel strips for first dimension isoelectric focusing (IEF) were rehydrated for at least $10 \mathrm{~h}$ before starting of IEF with $450 \mu \mathrm{L}$ rehydration buffer $(2 \mathrm{~mol} / \mathrm{L}$ Thiourea, 6 $\mathrm{mol} / \mathrm{L}$ Urea, 4\% CHAPS, $13 \mathrm{mmol} / \mathrm{L}$ DTT, 2\% pharmalyte pH 3-10, bromphenol blue).

Prior to IEF, $50 \mu \mathrm{g}$ of one Cy3-labelled control replicate, $50 \mu \mathrm{g}$ of one Cy5-labelled kairomone exposed replicate and $50 \mu \mathrm{g}$ of Cy2-labelled IPS were merged and $65 \mathrm{mmol} / \mathrm{L}$ DTT and 2\% pharmalyte $\mathrm{pH}$ 3-10 were added. This mixed sample was applied via anodic cup loading on one gel strip. IEF was performed using an IPGPhore (Pharmacia Biotech) with a total of $60 \mathrm{kV} \mathrm{h}$ per strip.

Before second dimension gel electrophoresis, gel strips were equilibrated for $15 \mathrm{~min}$ in $15 \mathrm{~mL}$ equilibration buffer $(50 \mathrm{mmol} / \mathrm{L}$ Tris- $\mathrm{HCl} \mathrm{pH} 6.8,6 \mathrm{~mol} / \mathrm{L}$ urea, $30 \%$ glycerin, $2 \%$ SDS) containing $1 \%$ DTT on a shaker (40 $\mathrm{min}^{-1}$, Certomat U, Sartorius). Afterwards, a second $15 \mathrm{~min}$ equilibration step in $15 \mathrm{~mL}$ equilibration buffer with $2.5 \%$ iodoacetamide and $200 \mu \mathrm{L}$ saturated bromphenol blue solution was performed. For second dimension electrophoresis, lab-cast $210 \times 260 \times 1 \mathrm{~mm}$ polyacrylamide gels $(1.5 \mathrm{~mol} / \mathrm{L}$ Tris- $\mathrm{HCl} \mathrm{pH} 8.8,12.5 \%$ acrylamide/bisacrylamide (37.5:1), 0.1\% SDS, 0.05\% APS, 0.05\% TEMED) and an ETTANDaltsix electrophoresis unit (GE Healthcare Life Sciences) were used. Equilibrated gel strips were fixed on top of the gels with the help of $0.5 \%$ agarose solved in SDS running buffer $(25 \mathrm{mmol} / \mathrm{L}$ Tris, $192 \mathrm{mmol} / \mathrm{L}$ glycine, $0.2 \% \mathrm{SDS}$ ). Electrophoresis was conducted at $10^{\circ} \mathrm{C}$ for one hour at $5 \mathrm{~W}$ per gel and afterwards at $17 \mathrm{~W}$ per gel until the dye front reached the end of the gel.

\section{Imaging and quantitative analysis}

Gels were scanned immediately after electrophoresis using a Typhoon 9400 fluorescence scanner (GE Healthcare Life Sciences) with parameters recommended for 2DDIGE experiments by the manufacturer. Image analysis and relative quantification were performed with $\mathrm{DeCy}-$ $\operatorname{der}^{\mathrm{ru}}$ 2D Software version v7.0 (GE Healthcare Life Sciences). Coordinates of significantly differing protein spots ( $p \leq 0.05$ with FDR correction, ratio $\geq|3|$ when comparing both treatments) were transferred to a pick list for further processing.

\section{Excision of spots and tryptic hydrolysis}

Gels were stained overnight with Coomassie Brilliant Blue (50\% Methanol, 0.5\% CBB R-250, 10\% acetic acid) and then destained for at least $8 \mathrm{~h}$. Spots of interest were cut 
out automatically with a PROTEINEER spII robot (Bruker Daltonics) using the created pick list. Next, spots were digested using a DigestPro MS robot (Intavis) with the following protocol: (i) wash step with $60 \mu \mathrm{L} 50 \mathrm{mmol} / \mathrm{L}$ $\mathrm{NH}_{4} \mathrm{HCO}_{3}$, (ii) wash step with $90 \mu \mathrm{L} 50 \%$ acetonitrile, 25 $\mathrm{mmol} / \mathrm{L} \mathrm{NH}_{4} \mathrm{HCO}_{3}$, (iii) $20 \mathrm{~min}$ wash in $60 \mu \mathrm{L}$ acetonitrile, (iv) $20 \mathrm{~min}$ wash in $60 \mu \mathrm{L} 50 \mathrm{mmol} / \mathrm{L} \mathrm{NH}_{4} \mathrm{HCO}_{3}$, (v) 20 min wash in $60 \mu \mathrm{L}$ acetonitrile, (vi) 15 min wash in $60 \mu \mathrm{L}$ acetonitrile, (vii) addition of $90 \mathrm{ng}$ porcine trypsin (Promega) in $15 \mu \mathrm{L} 50 \mathrm{mmol} / \mathrm{L} \mathrm{NH}_{4} \mathrm{HCO}_{3}$ and incubation at $37^{\circ} \mathrm{C}$ for $6 \mathrm{~h}$, (viii) addition of $15 \mu \mathrm{L} 2.5 \%$ formic acid. Samples were than dried in a vacuum centrifuge (Vacuum Concentrator, Bachofer) and stored at $-20^{\circ} \mathrm{C}$ until mass spectrometric analysis.

\section{LC-MS/MS analysis}

Nano-flow liquid chromatography tandem mass-spectrometry (nano-LC MS/MS) was performed with a nano LC ultra chromatographic device (Eksigent) coupled to a LTQ mass spectrometer (Thermo Scientific). Samples were resolved in $0.1 \%$ formic acid under 10 min sonication (Sonorex RK100, Bandelin). Subsequently, $10 \mu \mathrm{L}$ of each sample were injected and loaded on a C18 trap column (C18 PepMap100, particle size: $5 \mu \mathrm{m}, 100 \AA$, column size: $300 \mu \mathrm{m} \times 50 \mathrm{~mm}$, Dionex) for $10 \mathrm{~min}$ at a flow rate of $5 \mu \mathrm{min}^{-1}$ using mobile phase A ( $0.1 \%$ formic acid). RP chromatography was done at a flow-rate of $280 \mathrm{nLmin}^{-1}$ using a Reprosil-Pur C18 separation column (Reprosil-Pur C18 AQ, $3 \mu \mathrm{m}, 150 \mathrm{~mm} \times 75 \mu \mathrm{m}$ (ID), Dr. Maisch) with a 30 min linear gradient from $0 \%$ to $60 \%$ mobile phase B (A: $0.1 \%$ formic acid, B: $84 \%$ acetonitrile and $0.1 \%$ formic acid). For electrospray ionisation a distal coated Silica Tip (FS-360-50-15-D-20, New Objective) with a needle voltage of $1.4 \mathrm{kV}$ was used. The MS method consisted of a cycle combining one full MS scan (Mass range: $300-$ $2000 \mathrm{~m} / \mathrm{z}$ ) with three data dependant MS/MS events (35\% collision energy). The dynamic exclusion was set to $30 \mathrm{~s}$.

\section{Bioinformatic processing}

The MS/MS data were searched with Mascot Version: 2.3.00 (Matrix Science) using the following parameters: i) Enzyme: Trypsin; ii) Fixed Modification: Carbamidomethyl (C); iii) Variable modifications: Oxidation (M); iv) Peptide tol. 2 Da; v) MS/MS tol. 0.8 Da; vi) Peptide charge 1+, 2+ and 3+; vii) Instrument ESI-TRAP and viii) Allow up to 1 missed cleavages. As database, pre-released gene-predictions of D. magna (V2.4 effective 05/2012) were used. These sequence data were produced by The Center for Genomics and Bioinformatics at Indiana University and distributed via wFleaBase in collaboration with the Daphnia Genomics Consortium (http://daphnia.cgb. indiana.edu). Here, redundant entries of $90 \%$ similarity or more were detected through the software cd-hit [80] and removed. In addition, a common contaminants database (Max Planck Institute of Biochemistry, Martinsried, Germany: http://maxquant.org/contaminants.zip) was added. Mascot data were further processed with Scaffold 3 (Proteome Software), here "Protein Probability" and "Peptide Probability" were set to $99 \%$ and at least 2 unique peptides were used for protein identification.

Data were further processed with customised R scripts [81] (see also Additional file 5). Protein sequences were compared to data of NCBI nr [82] database using the NCBI Basic Local Alignment Search Tool (BLAST, $e-$ value $<0.001$ ) algorithm with R Package Bio3d [83].

GI numbers resulting from NCBI nr search were converted to UniProt accession numbers and further processed using the R biomaRt package [84] to gain further information on protein names and annotations, which are not yet available for preliminary D. magna sequence data. If no meaningful protein name was available for the first blast hit, which means that the protein name was either "uncharacterised" or a alphanumeric combination, further results were searched and added to the protein result. In addition, FlyBase Gene ID was looked up for the first blast hit related to Drosophila melanogaster.

Hierarchical clustering and heatmap were generated using the $\mathrm{R}$ package gplots. Cluster analysis of protein annotation (two-sided hypergeometric with BenjaminiHochberg correction) and network visualisation (kappascore $\geq 0.3$ ) were performed using the software Cytoscape 2.8.3 [85] with the ClueGO plug-in v1.7 [39] using the Gene Ontology and KEGG databases for D. melanogaster and CluePedia plug-in v1.0.8 [86].

Protein data were compared to known tandem duplicated genes in D. pulex [8], summarised in http://wfleabase.org/genome-summaries/gene-duplicates/ daphnia_tandemgene_table.html.

\section{Additional files}

Additional file 1: Spectral counting data. Spectral counting data, resulting from analysis of mass-spectrometric raw files with Scaffold Software, for all analysed spots as compressed zip file, for more details see Additional file 3.

Additional file 2: Spot data. Data of all identified spots, for more details see Additional file 3.

Additional file 3: Readme. Readme explaining contents of supporting files in more detail.

Additional file 4: Overlay images of 2D-DIGE-Gels.

Additional file 5: R-scripts.

Competing interests

The authors declare that they have no competing interests. 


\section{Authors' contributions}

$\mathrm{CL}$, TF and GJA designed the study. CL conducted the induction experiment and provided samples for proteomic analysis. KAO conducted proteomic experiments, performed mass spectrometry analysis and conducted bioinformatic analysis of the data. TF supervised mass spectrometry analysis. $\mathrm{KAO}$ wrote the first draft of the manuscript and $\mathrm{CL}$, TF and GJA contributed substantially to revisions. All authors read and approved the final manuscript.

Authors' information

Georg J Arnold and Christian Laforsch share senior authorship.

\section{Acknowledgements}

We thank M. Kredler and E. Ossipova for excellent help with the rearing of Daphnia and Triops. Members of Laforsch and Arnold group helped during induction and proteomics experiments and gave comments on the manuscript. We thank two anonymous reviewers for valuable and helpful comments on the manuscript. This work is part of the EUROCORE STRESSFLEA project funded by European Science Foundation.

\section{Author details}

${ }^{1}$ Department Biology II, Ludwig-Maximilians-University Munich, Großhaderner Str. 2, 82152 Planegg-Martinsried, Germany. ${ }^{2}$ Laboratory for Functional Genome Analysis (LAFUGA), Gene Center, Ludwig-Maximilians-University Munich, Feodor-Lynen-Str. 25, 81377 München, Germany. ${ }^{3}$ Animal Ecology I, Bayreuth University, 95440 Bayreuth, Germany.

Received: 30 December 2013 Accepted: 7 April 2014

Published: 24 April 2014

\section{References}

1. Bradshaw AD: Evolutionary significance of phenotypic plasticity in plants. Adv Genet 1965, 13(1):115-155.

2. Pigliucci M: Phenotypic Plasticity: Beyond Nature and Nurture. Baltimore: Johns Hopkins University Press; 2001.

3. Via S, Gomulkiewicz R, De Jong G, Scheiner SM, Schlichting CD, Van Tienderen PH: Adaptive phenotypic plasticity: consensus and controversy. Trends Ecol Evol 1995, 10(5):212-217.

4. Agrawal AA: Phenotypic plasticity in the interactions and evolution of species. Science 2001, 294(5541):321-326. doi:10.1126/science.1060701.

5. Tollrian R, Harvell CD: The evolution of inducible defenses: current ideas. Ecol Evol Inducible Defenses 1999:306-321.

6. Riessen HP: Costs of predator-induced morphological defences in Daphnia. Freshwater Biol 2012, 57(7):1422-1433. doi:10.1111/j.13652427.2012.02805.x

7. Ebert D: Ecology, Epidemiology and Evolution of Parasitism in Daphnia. Bethesda (MD): National Library of Medicine (US), National Center for Biotechnology Information 2005. www.ncbi.nlm.nih.gov/books/ NBK2036/.

8. Colbourne JK, Pfrender ME, Gilbert D, Thomas WK, Tucker A, Oakley TH Tokishita S, Aerts A, Arnold GJ, Basu MK, Bauer DJ, Cáceres CE, Carmel L, Casola C, Choi J-H, Detter JC, Dong Q, Dusheyko S, Eads BD, Fröhlich T, Geiler-Samerotte Ka, Gerlach D, Hatcher P, Jogdeo S, Krijgsveld J, Kriventseva EV, Kültz D, Laforsch C, Lindquist E, Lopez J, et al.: The ecoresponsive genome of Daphnia pulex. Science 2011, 331(6017):555-561. doi:10.1126/science.1197761.

9. Laforsch C, Tollrian R: Cyclomorphosis and phenotypic changes. Vol. 3. Encyclopedia Inland Waters 2009, 3:643-650.

10. Weider L, Pijanowska J: Plasticity of Daphnia life histories in response to chemical cues from predators. Oikos 1993, 67(3):385-392.

11. Riessen H: Predator-induced life history shifts in Daphnia: a synthesis of studies using meta-analysis. Can J Fisheries Aquat Sci 1999, 56:2487-2494.

12. De Meester $L$, Weider $L$ : Depth selection behavior, fish kairomones, and the life histories of Daphnia hyalina $x$ galeata hybrid clones. Limnology Oceanography 1999, 44(5):1248-1258.

13. Dodson S, Havel J: Indirect prey effects: some morphological and life history responses of Daphnia pulex exposed to Notonecta undulata. Limnology Oceanography 1988, 33(6):1274-1285.
14. Lampert $W$ : The adaptive significance of diel vertical migration of zooplankton. Funct Ecol 1989, 3(1):21-27.

15. De Meester L: Genotype, fish-mediated chemical, and phototactic behavior in Daphnia magna. Ecology 1993, 74(5):1467-1474.

16. Krueger D, Dodson S: Embryological induction and predation ecology in Daphnia pulex. Limnology Oceanography 1981, 26(2):219-223.

17. Tollrian $R$, Laforsch C: Linking predator kairomones and turbulence: synergistic effects and ultimate reasons for phenotypic plasticity in Daphnia cucullata. Archiv für Hydrobiologie 2006, 167(1):135-146. doi:10.1127/0003-9136/2006/0167-0135.

18. Petrusek A, Tollrian R, Schwenk K, Haas A, Laforsch C: A "crown of thorns" is an inducible defense that protects Daphnia against an ancient predator. Proc Nat Acad Sci USA 2009, 106(7):2248-2252. doi:10.1073/pnas.0808075106.

19. Dodson S: Predation of Heterocope septentrionalis on two species of Daphnia: morphological defenses and their cost. Ecology 1984, 65(4):1249-1257.

20. Laforsch C, Ngwa W, Grill W, Tollrian R: An acoustic microscopy technique reveals hidden morphological defenses in Daphnia. Proc Nat Acad Sci USA 2004, 101(45):15911-15914. doi:10.1073/pnas. 0404860101

21. Rabus M, Söllradl T, Clausen-Schaumann H, Laforsch C: Uncovering ultrastructural defences in Daphnia magna - an interdisciplinary approach to assess the predator-induced fortification of the carapace. PloS one 2013, 8(6). doi:10.1371/journal.pone.0067856.

22. Ebert D: A genome for the environment. 2011, 331(6017):539-540. doi:10.1126/science.1202092.

23. Tollrian R, Leese F: Ecological genomics: steps towards unraveling the genetic basis of inducible defenses in Daphnia. BMC Bio/ 2010, 8(51). doi:10.1186/1741-7007-8-51.

24. Pijanowska J, Kloc M: Daphnia response to predation threat involves heat-shock proteins and the actin and tubulin cytoskeleton. Genesis 2004, 38(2):81-86. doi:10.1002/gene.20000.

25. Pauwels K, Stoks R, de Meester L: Coping with predator stress: interclonal differences in induction of heat-shock proteins in the water flea Daphnia magna. J Evol Biol 2005, 18(4):867-872. doi:10.1111/j.1420-9101.2005.00890.x.

26. Schwarzenberger A, Courts C, von Elert E: Target gene approaches: Gene expression in Daphnia magna exposed to predator-borne kairomones or to microcystin-producing and microcystin-free Microcystis aeruginosa. BMC Genom 2009, 10(527). doi:10.1186/ 1471-2164-10-527.

27. Jansen M, Vergauwen L, Vandenbrouck T, Knapen D, Dom N, Spanier KI, Cielen A, De Meester L: Gene expression profiling of three different stressors in the water flea Daphnia magna. Ecotoxicology 2013, 22(5):900-914. doi:10.1007/s10646-013-1072-y.

28. Vogel C, Abreu RDS, Ko D, Le S-Y, Shapiro Ba, Burns SC, Sandhu D, Boutz $D R$, Marcotte EM, Penalva LO: Sequence signatures and mRNA concentration can explain two-thirds of protein abundance variation in a human cell line. Mol Syst Biol 2010, 6(400). doi:10.1038/ msb.2010.59.

29. Schwanhäusser B, Busse D, Li N, Dittmar G, Schuchhardt J, Wolf J, Chen W, Selbach M: Global quantification of mammalian gene expression control. Nature 2011, 473(7347):337-342. doi:10.1038/nature10098.

30. Benzie JAH: The Genus Daphnia (including Daphniopsis): (Anomopoda Daphniidae). vol. 21. Ghent: Kenobi Productions; 2005

31. Rabus M, Laforsch C: Growing large and bulky in the presence of the enemy Daphnia magna gradually switches the mode of inducible morphological defences. Funct Ecol 2011, 25(5):1137-1143. doi:10.1111/j.1365-2435.2011.01840.x.

32. Rabus M, Waterkeyn A, van Pottelbergh N, Brendonck L, Laforsch C: Interclonal variation, effectiveness and long-term implications of Triops-induced morphological defences in Daphnia magna Strauss. J Plankton Res 2012, 34(2):152-160. doi:10.1093/plankt/fbr092.

33. Fröhlich T, Arnold GJ, Fritsch R, Mayr T, Laforsch C: LC-MS/MS-based proteome profiling in Daphnia pulex and Daphnia longicephala: the Daphnia pulex genome database as a key for high throughput proteomics in Daphnia. BMC Genom 2009, 10(171). doi:10.1186/ 1471-2164-10-171.

34. Zeis B, Lamkemeyer T, Paul RJ, Nunes F, Schwerin S, Koch M, Schütz W, Madlung J, Fladerer C, Pirow R: Acclimatory responses of the Daphnia 
pulex proteome to environmental changes. I. Chronic exposure to hypoxia affects the oxygen transport system and carbohydrate metabolism. BMC Physiol 2009, 9(7). doi:10.1186/1472-6793-9-7.

35. Schwerin S, Zeis B, Lamkemeyer T, Paul RJ, Koch M, Madlung J, Fladerer C, Pirow R: Acclimatory responses of the Daphnia pulex proteome to environmental changes. II. Chronic exposure to different temperatures $\left(10^{\circ} \mathrm{C}\right.$ and $\left.20^{\circ} \mathrm{C}\right)$ mainly affects protein metabolism. BMC Physiol 2009, 9(8). doi:10.1186/1472-6793-9-8.

36. Kemp CJ, Kültz D: Controlling Proteome Degradation in Daphnia pulex. J Exp Zool 2012, 317(10):645-651. doi:10.1002/jez.1766.

37. Schwarzenberger A, Zitt A, Kroth P, Mueller S, Von Elert E: Gene expression and activity of digestive proteases in Daphnia: effects of cyanobacterial protease inhibitors. BMC Physio/ 2010, 10(6).

38. Laforsch C, Tollrian R: Embryological aspects of inducible morphological defenses in Daphnia. J Morphol 2004, 262(3):701-707.

39. Bindea G, Mlecnik B, Hackl H, Charoentong P, Tosolini M, Kirilovsky A, Fridman W-H, Pagès F, Trajanoski Z, Galon J: ClueGO: a Cytoscape plug-in to decipher functionally grouped gene ontology and pathway annotation networks. Bioinformatics 2009, 25(8):1091-1093. doi:10.1093/bioinformatics/btp101.

40. Lima SL, Dill LM: Behavioral decisions made under the risk of predation: a review and prospectus. Can J Zool 1990, 68(4):619-640.

41. Herzog Q, Laforsch C: Modality matters for the expression of inducible defenses: introducing a concept of predator modality. BMC Biol 2013, 11:113. doi:10.1186/1741-7007-11-113.

42. Hettyey A, Vincze K, Zsarnóczai S, Hoi H, Laurila a: Costs and benefits of defences induced by predators differing in dangerousness. J Evol Biol 2011, 24(5):1007-1019. doi:10.1111/j.1420-9101.2011.02233.x.

43. Dodson S: Zooplankton competition and predation: an experimental test of the size-efficency hypothesis. Ecology 1974, 55(3):605-613.

44. Ferl RJ, Manak MS, Reyes MF: The 14-3-3s. Genome Biol 2002, 3(7):1-7.

45. Tabunoki H, Shimada T, Banno Y, Sato R, Kajiwara H, Mita K, Satoh J-i: Identification of Bombyx mori 14-3-3 orthologs and the interactor Hsp60. Neurosci Res 2008, 61(3):271-280. doi:10.1016/j.neures.2008. 03.007.

46. Lee $S$, Feldman R, O'Farrell P: An RNA interference screen identifies a novel regulator of target of rapamycin that mediates hypoxia suppression of translation in Drosophila S2 cells. Mol Bio/ Cell 2008, 19(October):4051-4061. doi:10.1091/mbc.E08.

47. Kregel KC: Heat shock proteins: modifying factors in physiological stress responses and acquired thermotolerance. J Appl Physiol (Bethesda, Md.: 1985) 2002, 92(5):2177-2186. doi:10.1152/japplphysiol. 01267.2001

48. Sörensen JG, Kristensen TN, Loeschcke V: The evolutionary and ecological role of heat shock proteins. Ecol Lett 2003, 6(11):1025-1037. doi:10.1046/j.1461-0248.2003.00528.x.

49. Haap T, Köhler H-R: Cadmium tolerance in seven Daphnia magna clones is associated with reduced hsp70 baseline levels and induction. Aquat Toxicol 2009, 94(2):131-137. doi:10.1016/j.aquatox. 2009.06.006.

50. Nuell M, Stewart D: Prohibitin, an evolutionarily conserved intracellular protein that blocks DNA synthesis in normal fibroblasts and HeLa cells. Mol Cell Biol 1991, 11(3):1372-1381. doi:10.1128/ MCB.11.3.1372.Updated.

51. Eveleth D, Marsh J: Sequence and expression of the Cc gene, a member of the dopa decarboxylase gene cluster of Drosophila: possible translational regulation. Nucleic Acids Res 1986, 14(15):6169-6184.

52. Arbouzova NI, Zeidler MP: JAK/STAT signalling in Drosophila: insights into conserved regulatory and cellular functions. Dev (Cambridge, England) 2006, 133(14):2605-2616. doi:10.1242/dev.02411.

53. Mukherjee T, Hombría JC-G, Zeidler MP: Opposing roles for Drosophila JAK/STAT signalling during cellular proliferation. Oncogene 2005 24(15):2503-2511. doi:10.1038/sj.onc.1208487.

54. Subramoniam T: Mechanisms and control of vitellogenesis in crustaceans. Fisheries Sci 2010, 77(1):1-21. doi:10.1007/s12562-010 0301-z.

55. Sappington TW, Raikhel AS: Molecular characteristics of insect vitellogenins and vitellogenin receptors. Insect Biochem Mol Biol 1998, 28(5-6):277-300.

56. Romano M, Rosanova P, Anteo C, Limatola E: Vertebrate yolk proteins: a review. Mol Reprod Dev 2004, 69(1):109-116. doi:10.1002/mrd.20146.
57. Raikhel AS, Dhadialla TS: Accumulation of yolk proteins in insect oocytes. Ann Rev Entomol 1992, 37:217-251. doi:10.1146/annurev. en.37.010192.001245

58. Byrne B, Gruber M, Ab G: The evolution of egg yolk proteins. Prog Biophys Mol Biol 1989, 53:33-69.

59. Stibor $\mathrm{H}$ : The role of yolk protein dynamics and predator kairomones for the life history of Daphnia magna. Ecology 2002, 83(2):362-369. doi:10.2307/2680020.

60. Boersma M, Spaak P, Meester LD: Predator-mediated plasticity in morphology, life history, and behavior of Daphnia: the uncoupling of responses. Am Nat 1998, 152(2):237-248.

61. Pauwels K, Stoks R, De Meester L: Enhanced anti-predator defence in the presence of food stress in the water flea Daphnia magna. Func Ecol 2010, 24(2):322-329. doi:10.1111/j.1365-2435.2009.01641.x.

62. Coors A, Hammers-Wirtz M, Ratte HT: Adaptation to environmental stress in Daphnia magna simultaneously exposed to a xenobiotic. Chemosphere 2004, 56(4):395-404. doi:10.1016/j.chemosphere.2004 04.025 .

63. Hesse $\mathrm{O}$, Engelbrecht W, Laforsch C, Wolinska J: Fighting parasites and predators: how to deal with multiple threats? BMC ECO/ 2012, 12(12) doi:10.1186/1472-6785-12-12.

64. Sheterline P, Clayton J, Sparrow JC: Actin. Oxford: OUP Oxford; 1999.

65. Fyrberg EA, Mahaffey JW, Bond BJ, Davidson N: Transcripts of the six Drosophila actin genes accumulate in a stage- and tissue-specific manner. Cell 1983, 33(1):115-123.

66. Röper K, Mao Y, Brown NH: Contribution of sequence variation in Drosophila actins to their incorporation into actin-based structures in vivo. J Cell Sci 2005, 118(Pt 17):3937-3948. doi:10.1242/jcs.02517.

67. Hooper SL, Hobbs KH, Thuma JB: Invertebrate muscles: thin and thick filament structure; molecular basis of contraction and its regulation, catch and asynchronous muscle. Prog Neurobiol 2008, 86(2):72-127. doi:10.1016/j.pneurobio.2008.06.004

68. Margulis B, Bobrova I: Major myofibrillar protein content and the structure of mollusc adductor contractile apparatus. Comp Biochem Physiol 1979, 64A:291-298.

69. Reimer $\mathrm{O}$, Harms-Ringdahl S: Predator-inducible changes in blue mussels from the predator-free Baltic Sea. Mar Biol 2001 139(5):959-965. doi:10.1007/s002270100606.

70. Anderson BG: Regeneration in the carapace of Daphnia magna. Biol Bull 1933, 64(1):70-85

71. Halcrow K, John S, Brunswick N: The fine structure of the carapace integument of Daphnia magna. Cell Tissue Res 1976, 276:267-276.

72. Andersen SO: Mini-review insect cuticular proteins. Insect Biochem Mol Biol 1995, 25(2):153-176

73. Skinner D, Kumari S, O'brien J: Proteins of the crustacean exoskeleton. Am Zool 1992, 32(3):470-484.

74. Vincent JFV, Wegst UGK: Design and mechanical properties of insect cuticle. Arthropod Struct Dev 2004, 33(3):187-199. doi:10.1016/j.asd.2004. 05.006

75. Sigrist CJa, de Castro E, Cerutti L, Cuche BA, Hulo N, Bridge A, Bougueleret $L$, Xenarios I: New and continuing developments at PROSITE. Nucleic Acids Res 2013, 41(Database issue):344-347. doi:10.1093/nar/gks1067.

76. Reberst JE, Riddifordt LM: Structure and Expression of a Manduca sexta larval cuticle gene homologous to drosophila cuticle genes. J Mol Biol 1988, 203:411-423.

77. Andersen SO: Amino acid sequence studies on endocuticular proteins from the desert locust, Schistocerca gregaria. Insect Biochem Mol Biol 1998, 28(5-6):421-434

78. Arakane Y, Dixit R, Begum K, Park Y, Specht CA, Merzendorfer H, Kramer KJ, Muthukrishnan S, Beeman RW: Analysis of functions of the chitin deacetylase gene family in Tribolium castaneum. Insect Biochem Mol Biol 2009, 39(5-6):355-365. doi:10.1016/j.ibmb.2009.02.002.

79. Laforsch C, Beccara L, Tollrian R: Inducible defenses: The relevance of chemical alarm cues in Daphnia. Limnol Oceanography 2006, 51(3):1466-1472. doi:10.4319//o.2006.51.3.1466.

80. Huang Y, Niu B, Gao Y, Fu L, Li W: CD-HIT Suite: a web server for clustering and comparing biological sequences. Bioinformatics 2010 26(5):680-682. doi:10.1093/bioinformatics/btq003.

81. R Development Core Team: R: A Language and Environment for Statistical Computing. Vienna, Austria: R Foundation for Statistical Computing; 2011. http://www.r-project.org/. 
82. Geer LY, Marchler-Bauer A, Geer RC, Han L, He J, He S, Liu C, Shi W, Bryant SH: The NCBI BioSystems database. Nucleic Acids Res 2010, 38(suppl 1):492-496.

83. Grant BJ, Rodrigues APC, ElSawy KM, McCammon JA, Caves LSD: Bio3D: An $\mathrm{R}$ package for the comparative analysis of protein structures. Bioinformatics 2006, 22:2695-2696.

84. Durinck S, Spellman PT, Birney E, Huber W: Mapping identifiers for the integration of genomic datasets with the R/Bioconductor package biomaRt. Nature Protocols 2009, 4(8):1184-91.

85. Smoot ME, Ono K, Ruscheinski J, Wang P-L, Ideker T: Cytoscape 2.8: new features for data integration and network visualization. Bioinformatics 2011, 27(3):431-432. doi:10.1093/bioinformatics/btq675.

86. Bindea G, Galon J, Mlecnik B: CluePedia Cytoscape plugin: pathway insights using integrated experimental and in silico data.

Bioinformatics (Oxford, England) 2013, 29(5):661-663. doi:10.1093/ bioinformatics/btt019.

doi:10.1186/1471-2164-15-306

Cite this article as: Otte et al.: Proteomic analysis of Daphnia magna hints at molecular pathways involved in defensive plastic responses. BMC Genomics 2014 15:306.

Submit your next manuscript to BioMed Central and take full advantage of:

- Convenient online submission

- Thorough peer review

- No space constraints or color figure charges

- Immediate publication on acceptance

- Inclusion in PubMed, CAS, Scopus and Google Scholar

- Research which is freely available for redistribution

Submit your manuscript at www.biomedcentral.com/submit
C Biomed Central 